$\xi=$

\title{
Spatial-temporal distribution of the black rhino population in the Ngorongoro Crater, Tanzania
}

\author{
Donatus E. Gadiye ${ }^{1 *}$, George W. Eshiamwatta, Wilfred O. Odadi ${ }^{2}$ \\ ${ }^{I}$ Ngorongoro Conservation Area, Department of conservation services, Tanzania \\ ${ }^{2}$ Egerton University, Department of Natural Resources \\ *Corresponding author E-mail:
}

\begin{abstract}
Ngorongoro Conservation Area (NCA) is vital especially for black rhino conservation because it is one of the only two ecosystems in Tanzania that host native black rhino populations. However, the spatial-temporal distribution of rhinos in this ecosystem have not been assessed. The purpose of this study was to assess the temporal and spatial distribution of rhinos and factors responsible for the uneven seasonal distribution. The study was conducted in Ngorongoro Conservation Area (NCA) which is located at $3^{\circ} 12^{\prime} \mathrm{S}, 35^{\circ} 27^{\prime} \mathrm{E}$ during the wet (May-June 2015) and dry (August-September 2015) sampling periods. Road drives were conducted daily for a period of one month during each season to map the spatial distribution of the black rhino, and assess the relative abundance of its forage resources and diet selection. During each drive, the roadsides were inspected for the presence of rhinos, with stops being made each time an individual or group of rhinos is located. Results shows that the distribution patterns of the black rhino differed markedly between wet and dry sampling periods. During the dry period, rhinos were mainly concentrated in the crater slopes dominated by shrubby vegetation, swamps and along riverine areas of the crater. During wet season in there were more herbage material mostly preferred by black rhino in crater floor as most rhinos were sighted in these sampling areas. Human activities such as tourism infrastructure (lodges, campsites and roads) should be kept minimal to minimize disruption to rhino movement and habitat selection patterns and buffer zones be established within cratercommunity interfaces where human activities such as livestock grazing are strictly prohibited to ensure natural distribution ranges are maintained.
\end{abstract}

Keywords: Black, Rhino, spatial, distribution, Ngorongoro

\section{Introduction}

Black rhinos (Dicerosbicornis) were once abundant in many parts of Africa, especially in eastern and southern Africa (Dobson et al., 1992). However, since 1970s most of the black rhino populations have effectively been eliminated from a large part of their historical range. It is estimated that the black rhino numbers have reduced by $95 \%$ from 65,000 to 3,500 individuals (Hearne and Swart, 1991). The massive declines in black rhino numbers have been attributed to rampant poaching within its ranges. Currently, native black rhino populations are only found in Tanzania, Kenya, South Africa and Botswana. Most of the extant black rhino populations in these countries are found within government protected areas and well managed private wildlife conservancies (Blake et al., 2007). In Tanzania, the remnant black rhino populations primarily occur in Ngorongoro Conservation Area, Selous Game Reserve, Serengeti National Park and Mkomazi National Park (Makacha et al., 1982; Sinclair, 1995).

Ngorongoro Conservation Area (NCA) is vital especially for black rhino conservation because it is one of the only two ecosystems in Tanzania that host native black rhino populations. The black rhino population in the NCA is almost exclusively concentrated in the Ngorongoro Crater, which forms just $4 \%$ of the NCA area. The population of black rhinos in NCA has dramatically declined since the mid-20 $2{ }^{\text {th }}$ century, and especially since 1960 s as a result of illegal poaching to supply the growing demand for rhinoceros' horn
(Martin, 1992; 1997). The NCA black rhino population decline continued throughout 1980s and is it is estimated that over $95 \%$ of the population that existed in 1960s (approximately 108 individuals) was eliminated (Bret, 2010).

In order to curb poaching and enhance the recovery of the black rhino population in the Ngorongoro Conservation Area, several conservation and security measures have been put in place, including 24-hour surveillance of the crater through car and foot patrols. In addition, population censuses are carried out regularly. However, little is known about black rhino population trends in this ecosystem over the past years since the inception of these conservation efforts. Understanding the demographics and distribution of the species is important in assessing the resilience, long-term persistence or vulnerability of this population to vagaries of extinction or extirpation. In addition, seasonal distribution of black rhino and factors influencing the distribution has not yet been documented.

\section{Materials and methods}

\subsection{Study area}

The study was conducted in Ngorongoro Conservation Area (NCA) which is located at $3^{\circ} 12^{\prime} \mathrm{S}, 35^{\circ} 27^{\prime} \mathrm{E}$ during the wet (MayJune 2015) and dry (August-September 2015) sampling periods. The NCA covers a total area $8,292 \mathrm{~km}^{2}$. The NCA was established 
in 1959 as a multiple land use area where wildlife and human activities coexisted. The main feature of the Ngorongoro Conservation Area is the Ngorongoro Crater, the world's largest inactive, intact, and unfilled volcanic caldera. Estimates of the height of the original volcano range from 4,500 to $5,800 \mathrm{~m}(14,800$ to 19,000 feet) high. Its climatic zones range from semi-arid to montane forest, all of it accounts to widely ranging levels of precipitation (from under $500 \mathrm{~mm}$ to $1700 \mathrm{~mm}$ ) and annual average temperature oscillate between $2^{\circ} \mathrm{C}$ to $35^{\circ} \mathrm{C}$. The crater floor is much hotter than the rim, which is often swathed in morning fog, and depending on the time of the year, can range from warm to chilly to freezing at night. The crater highlands on the forested eastern slopes facing the easterly trade winds receives 800 to $1500 \mathrm{~mm}$ of rain a year and the less-steep west wall receives only 400 to $600 \mathrm{~mm}$ of rainfall and covered by thickets, shrubs and other grassland vegetation. The crater is generally dry in months of January and February, May to July and wet during moths of April and August. However, the western plains are particularly dry during
February and between June and September. It therefore consists of micro-habitat that includes a saline lake, swamp, plain and forest.

The Ngorongoro Crater has global importance for biodiversity conservation due to the presence of globally threatened species, the density of wildlife inhabiting the area, and the annual migration of wildebeest, zebra, gazelles and other animals into the northern plains. Approximately 25,000 large animals, mostly ungulates, live in the crater. Large animals in the crater include the black rhino (Dicerosbicornis), the local population of which declined from about 108 in year 1964-66 to between 11-14 in year 1995, the African buffalo (Synceruscaffer), and the Hippopotamus (Hippopotamus amphibius). There also are many other ungulates: the wildebeest (Connochaetes taurinus) (7,000 estimated in year 1994), Burchell's zebra (Equus burchelli) $(4,000)$, the common eland (Taurotragus oryx), and Grant's (Gazellagranti) and Thomson's gazelles (Gazella thomsoni) $(3,000)$.

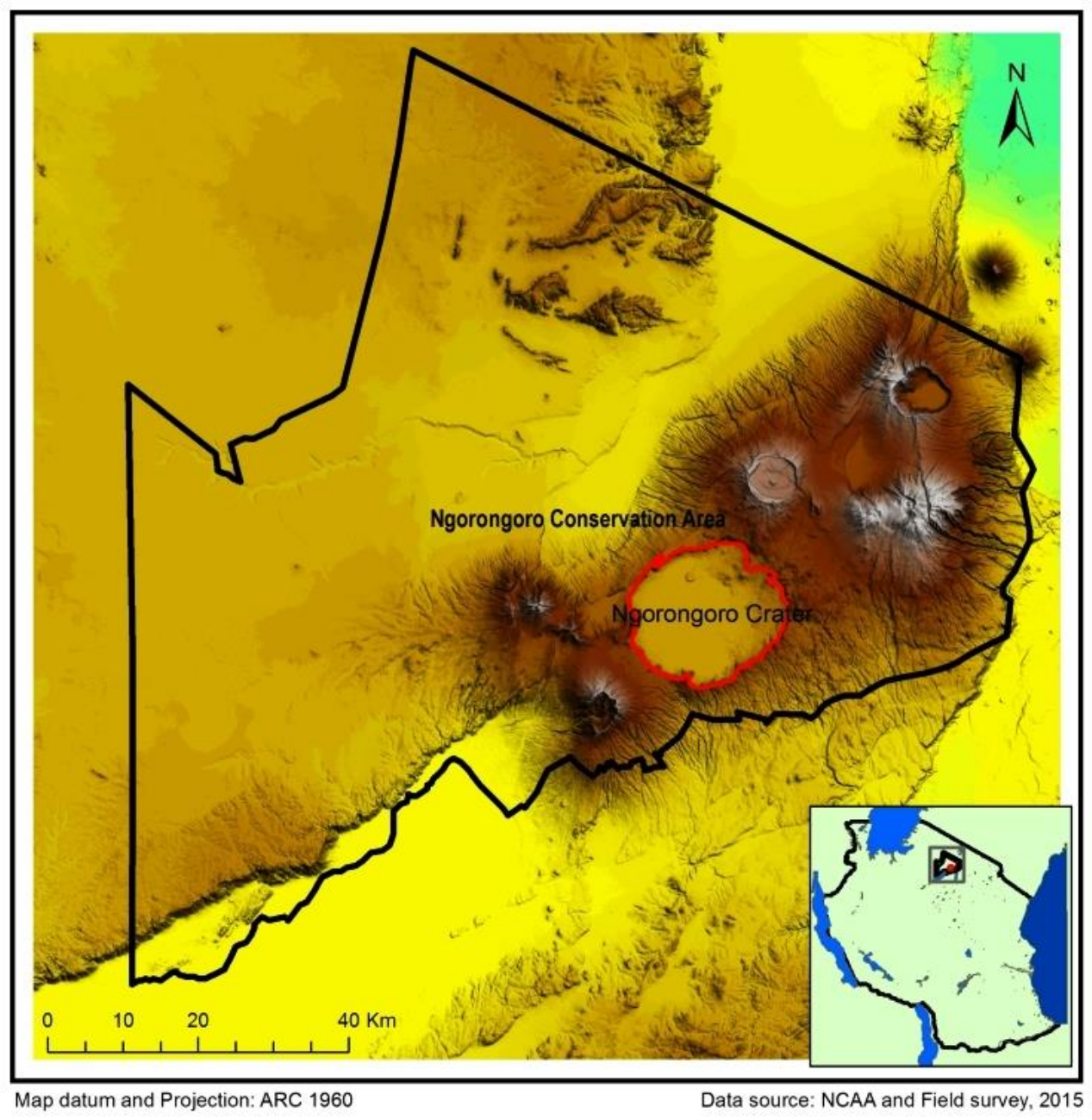

Fig.1: Map of Ngorongoro Conservation Area.

\subsection{Data collection}

Road drives were conducted daily for a period of one month during each season to map the spatial distribution of the black rhino, and assess the relative abundance of its forage resources. During each drive, the roadsides were inspected for the presence of rhinos, with stops being made each time an individual or group of rhinos is located. In addition, rhinos were located from 13 established ranger observation points distributed strategically within the crater. The approximate position of any sighted individual or group was marked using any conspicuous landmarks. Subsequently, the rhinos were observed from a safe distance using a pair of binoculars and group sizes were recorded. Efforts were made to ensure minimal interference with the normal behavior of rhinos during location and observation. Once the individual or group of rhinos under observation moved to a safe distance, its original location was accessed (either by car or by foot) and the geographical position recorded using a hand-held GPS.

\section{Results}

\subsection{Spatial distribution of the black rhino in ngorongo- ro crater}

The distribution patterns of the black rhino differed markedly between wet (May-June 2015) and dry (August-September 2015) 
sampling periods (Fig. 1). During the dry period, rhinos were mainly concentrated in the crater slopes dominated by shrubby vegetation, swamps and along riverine areas of the crater. The distribution of rhinos in the crater is influenced greatly by forage items as proxy of seasonal variation. During wet season in (MayJune 2015) there was more herbage material mostly preferred by black rhino in crater floor as most rhinos were sighted in these sampling areas. However during dry sampling period (AugustSeptember 2015), most rhinos were sighted in crater slopes and crater rims. These areas were dominated by perennial shrubs and thickets that are alternatives forage items of rhino when succulent forbs are unavailable.

On the crater floors, rhinos were sighted only areas with water sources such as Mandusi swamps, Gorikor swamps and Ngoitoktok springs. Most spatial distribution during dry season were in forest and shrubland especially, Lerai forest. However, large herds of rhinos were more common in wet season too in Lerai forest as it is rich in forage herbaceous and preferred shrubs and trees such as Acacia xanthophloea.

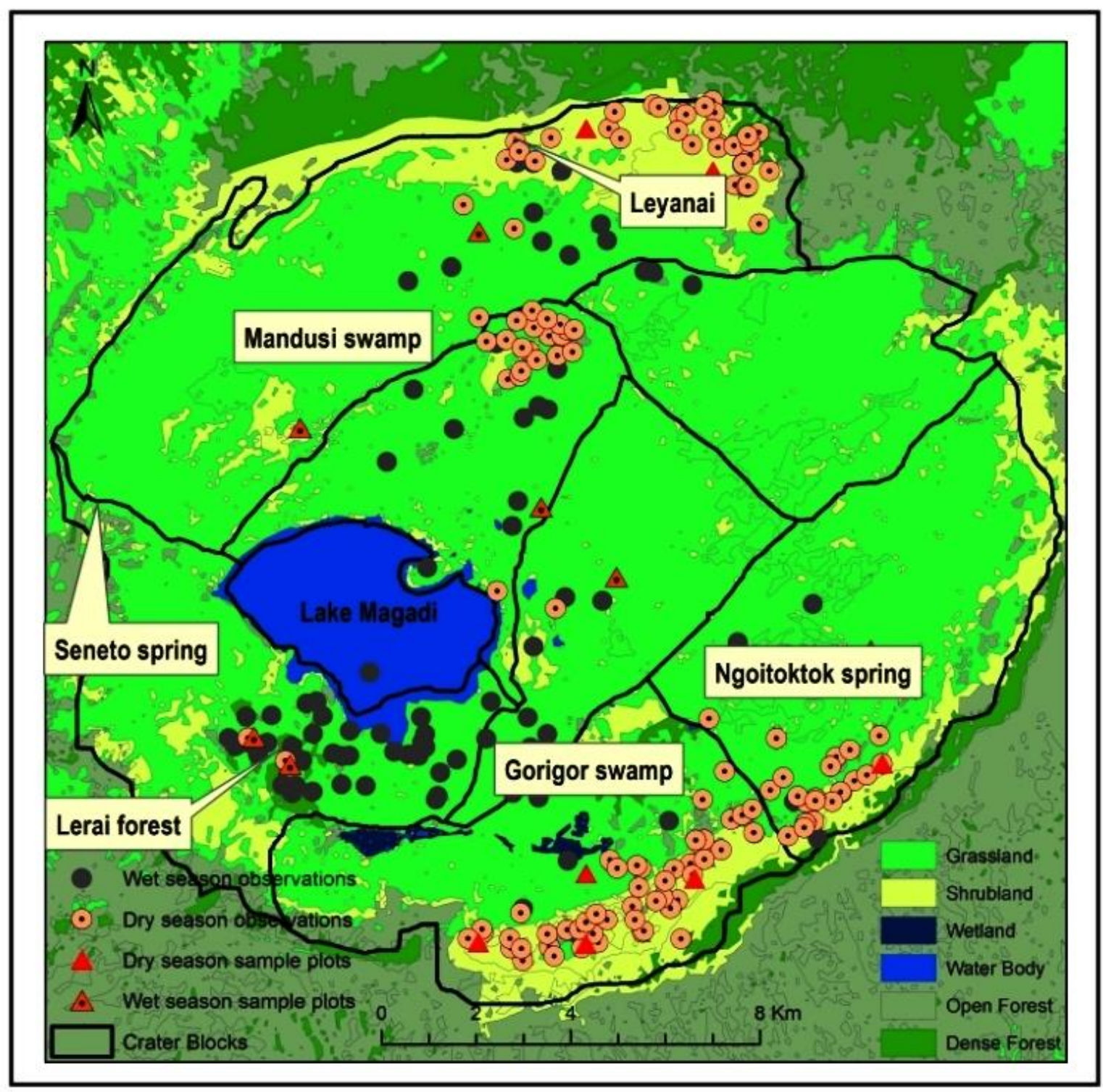

Fig.1:Rhino Distribution across Ngorongoro Crater during May-June 2015 (Wet Season) and August-September 2015 (Dry Season). 


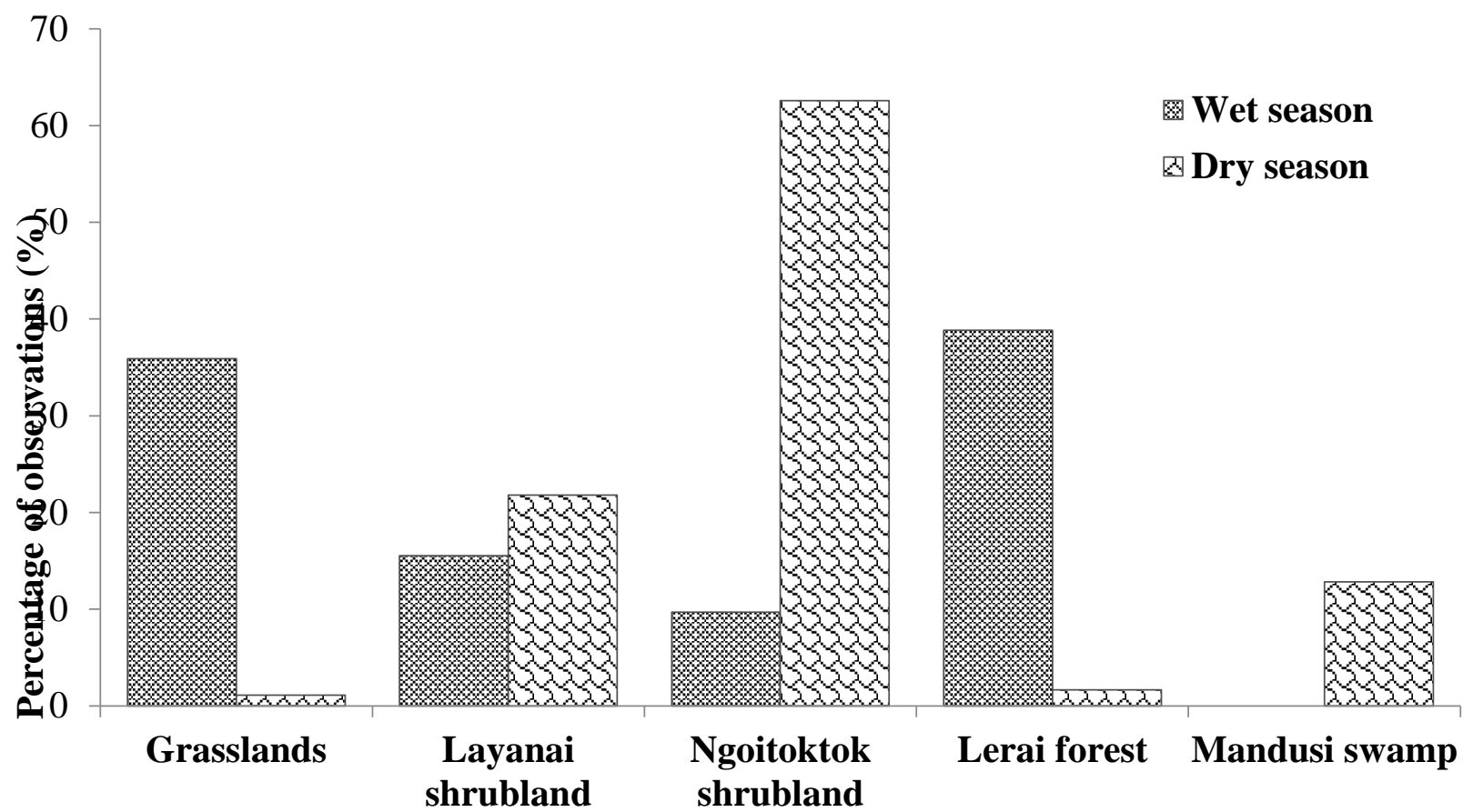

Fig. 2: Percentage Sightings of Black Rhinos across Different Vegetation Types in Ngorongoro Crater during May-June 2015 (Wet Season) and AugustSeptember 2015 (Dry).

In the crater walls the black rhinos were largely sighted on the southern inner walls of the crater (63\%), in Leyanai area (22\%), and in crater floor swamps. Moreover, some individuals were seen in the small perched forest of Lerai in the western side of the crater floor. In the wet period, however, rhinos were found mainly in crater floor mostly in areas around Lake Magadi and near Lerai forest. Notably, the rhinos avoided areas west and east of crater in both sampling periods. Human activities were evident in these areas avoided by rhinos such as infrastructure i.e. roads, tourist lodges and campsites as well as transhumance by local Masai community.

\section{Discussion}

The disparity in the spatial distribution patterns of the black rhino between sampling periods was likely driven by seasonal differences in forage availability and quality which in turn influenced selection of foraging sites. In the wet period when forbs were abundant and of high nutritional quality, the rhinos were mostly sighted on the crater floor. However, in the dry sampling period when forbs were apparently less abundant and apparently of poor nutritional quality, the rhinos were most frequently observed on the crater slopes dominated by shrubs. The black rhino distribution patterns observed in this study demonstrates that this species uses a variety of habitat types, including shrubland, open grasslands, closed canopy forests and swampy areas.

The observed rhino distribution patterns across different habitat types are consistent with the findings of past studies elsewhere (Oloo et al., 1994, Tatan et al., 2000; Buk and Knight, 2012). These studies generally indicate that black rhinos utilize a variety of habitat types including shrubland, woodlands and marshlands. The observed rhino distribution pattern is also related to human activity. Specifically, rhinos avoided the eastern and western parts of the crater during both seasons possibly due to anthropogenic disturbances in these areas. The western part of the crater is frequented by local community herders and their livestock for purposes of accessing water and salt licks. This area is also used as descent road into the crater floor by tourists. In addition, the western slopes contain an ascent road, tourist lodges and campsites. Likewise, the eastern part of the crater has a road used to both descend and ascend. Total avoidance of these areas by rhinos indicates that rhinos have zero tolerance to all sorts of disturbances from human.
According to Brett (2001) human-related impacts on rhinos have clearly been evident in the 'crowding' by tourist vehicles of rhinos during daily movements between forest and plains. The spatial distribution of the present rhino population now covers a small proportion of the total area of the crater formerly used by the black rhinos. Although the 61 rhinos recorded by Sinclair and Arcese, (1995) were mostly found in the central area of the crater, all intervening reports up to the mid-1980 record the rhinos using most of the crater floor, including northern and western sectors where rhinos were not sighted in the present study. The rhino density noted by Sinclair and Arcese in the early 1980s (Sinclair and Arcese, 1995) was approximately $20 \%$ of that observed by Goddard (1968), but the 25 rhinos resident in 1980-82 were widespread, used most of the crater floor and had larger home ranges on average. According to another earlier study, rhinos frequented the Seneto/Mandusi area (Brett, 2001), which was not the case in the present study.

The distribution patterns of rhinos within the crater was explored by Landman et al. (2013) who discussed the possible changes in grass species composition accompanying these changes, the lack of burning of grasslands in the crater since the early 1970s and, in particular, the effects of isolation of the crater's large mammal fauna through increased settlement and recent increase in human population in the NCAA and numbers of their stock.

In this study it was evident that habitat usage by rhinos is influenced by seasonal variations. This finding is consistent with studies elsewhere. Ganqa et al. (2005) found out that wild rhinos fed most on herbs in thickets and in riverine habitats in the wet and early dry seasons, respectively. Van Lieverloo et al., (2009) concluded that rhino groups adjusted habitat usage for browsing according to season. Wild rhinos used most ColophospermumTerminalia- Combretum woodland and plains with abundant herbs in the wet season and thickets in the early dry season. Additionally, they (Van Lieverloo et al., 2009) found out that wild rhinos increased feeding in thickets and riverine areas in the early dry season compared to the wet season. Seasonal requirement for succulence (high-moisture food) could have been a major factor governing diet selection; choice of riverine habitats in the dry season would have exposed wild rhinos to a 'new' range of plant species from which to select. Riverine vegetation has a higher moisture content providing more 'green bite' during the dry season. Secondly, rhinos changed browse selection in response to browse phenological changes. Reduced palatability of browse in the dry 
season will induce a shift to more palatable species, as well as to other plant parts of the same species (Atkinson, 1995).

\section{Conclusion}

The distribution of black rhinos (Dicerous birconis) in Ngorongoro Conservation Area differed markedly in dry and wet season. This was influenced by variation if food profile, quality, composition, diversity and abundance in both seasons. Most rhino distribution sites during wet sampling period were in crater floor dominated by rich succulent forbs and herbaceous plants. In contrast, rhinos were distributed in crater slopes during wet seasons. Their distribution is also attributed to anthropogenic activities such as transhumance and tourism facilities such as roads, lodges and campsites which negatively influence their distribution.

\section{References}

[1] Atkinson, S.J. (1995). Maintenance of captive black rhinos (Dicerosbicornis) on indigenous browse in Zimbabwe: Energetics, nutrition and implications for conservation. MSc. Thesis. University of Zimbabwe

[2] Blake, S., Strindberg, S., Boundjan, P. and Makombo, C. (2007) "Forest elephant crisis in the Congo Basin". Public Library of Science 5: 945 - 953http://dx.doi.org/10.1371/journal.pbio.0050111.

[3] Bret, R. (2001). Investigation of black rhino mortalities at Ngorongoro crater, Tanzania: black rhino habitat and ecological requirements; Coordination with National and Continental Rhino Conservation Semester 4 Task 1.3-1.3

[4] Bret, R. (2010). SADC Regional Programme for Rhino Conservation: Investigation of black rhino mortalities in Ngorongoro Crater. Black rhino and ecological requirements

[5] Buk, K.G. and Knight, M.H. (2012). Habitat Suitability Model for black rhinoceros in Augrabies Falls National Park, South Africa South African Journal of Wildlife Research 42 (2):82. http://dx.doi.org/10.3957/056.042.0206.

[6] Dobson, A.P., Mace, G.M., Poole, J and Brett R.A (1992). Conservation Biology: The ecology and genetics of endangered species. Genes in Ecology: 33rd Symposium of the British Ecological Society, Cambridge University Press

[7] Ganqa, N.M., Scogings, P.F and Raats, J.G. (2005). Diet selection and forage quality factors affecting woody plant selection by black rhinoceros in the Great Fish River Reserve, South Africa. South African Journal of Wildlife Research 35(1): 77-83 (April 2005)

[8] Goddard, J. (1968). Food Preferences by black rhinoceros Populations. East African Wildlife Journal 6:118http://dx.doi.org/10.1111/j.1365-2028.1968.tb00898.x.

[9] Hearne, J.W. and Swart, J. (1991). Optimal translocation strategies for saving the black rhino. Ecological Modelling 59: 279http://dx.doi.org/10.1016/0304-3800(91)90182-Z.

[10] Landman, M, Schoeman, D.S, and Kerley, G.H (2013). Shift in black Rhinoceros Diet in the Presence of Elephant: Evidence for Competition? Journal pone 8(7) p 37-48

[11] Makacha, S., Msingwa, M.J. and Frame, W. (1982). Threats to the Serengeti herds. Oryx 16:437444.http://dx.doi.org/10.1017/S0030605300018111.

[12] Martin, E B. and Martin C.B. (1992). Run Rhino Run. London, Chato and Windus.

[13] Martin, E.B., Vigne, L. and Allan, C. (1997). On a knife edge: The rhinoceros horn trade in Yemen. TRAFFIC International, Cambridge

[14] Oloo, T.W., Brett, R. and Young, T.P. (1994). Seasonal variation in feeding ecology of black rhinoceros (Dicerosbicornis L.) in Laikipia, Kenya. African Journal of Ecology 32: 142157.http://dx.doi.org/10.1111/j.1365-2028.1994.tb00565.x.

[15] Roodt, V. (2012). Tourist Travel and Field Guide of Ngorongoro Coservation Area. Struik Lifestyle.

[16] Sinclair, A. R. and Arcese, P. (1995). Serengeti II: dynamics, management, and conservation of an ecosystem (Vol. 2). University of Chicago Press.

[17] Sinclair, A. R. and Arcese, P. (1995). Serengeti II: dynamics, management, and conservation of an ecosystem (Vol. 2). University of Chicago Press.

[18] Tatman, S.C., Stevens-Wood, B. and Smith, V.B.T. (2000) Ranging behaviour and habitat usage in black rhinoceros, Dicerosbicornis, in a Kenyan sanctuary. African Journal of Ecology 38, 163 172.http://dx.doi.org/10.1046/j.1365-2028.2000.00235.x.

[19] VanLieverloo, R. J., Schuiling, B. F., de Boer, W. F., Lent, P. C. de Jong, C. B., Brown, D., and Prins, H. H. (2009). A comparison of faecal analysis with back tracking to determine the diet composition and species preference of the black rhinoceros (Dicerosbicornis minor). European Journal of Wildlife Research, 55(5), 505515.http://dx.doi.org/10.1007/s10344-009-0264-5. 